Max-Planck-Institut für demografische Forschung

Max Planck Institute for Demographic Research

Konrad-Zuse-Strasse 1 - D-18057 Rostock · GERMANY

Tel +49 (0) 3812081 - 0; Fax +49 (0) 3812081 - 202;

http://www.demogr.mpg.de

MPIDR WORKING PAPER WP 2005-031

OCTOBER 2005

\title{
The emergence of cohabitation as a first union and its later stability: the case of Hungarian women
}

Margarete C. Kulik (kulik@demogr.mpg.de)

This working paper has been approved for release by: Gerda Ruth Neyer (neyer@ demogr.mpg.de) Deputy Head of the Laboratory of Contemporary European Fertility and Family Dynamics.

(C) Copyright is held by the authors.

Working papers of the Max Planck Institute for Demographic Research receive only limited review. Views or opinions expressed in working papers are attributable to the authors and do not necessarily reflect those of the Institute. 


\title{
The emergence of cohabitation as a first union and its later stability: the case of Hungarian women
}

\author{
Margarete C. Kulik \\ Rostock, 27.10.2005 \\ MPIDR Working Paper
}

\begin{abstract}
:
With the transition of the 1990s in the countries of Central and Eastern Europe, the demographic behavior of their populations has changed drastically. This paper focuses on Hungary where some of these developments like falling marriage rates were evident even before 1990. We examine the emergence of cohabitation as a first union and the stability of such relationships. Are they rather transformed into marriage or do they end in dissolution? How long do Hungarian woman stay in these unions?

In addition to some descriptive statistics we apply event history analysis because this allows us to study the impact of individual-level characteristics on such choices. The data used is the Hungarian Generations and Gender Survey collected around November 2001. The analysis shows that there are marked differences in behavior between periods and that factors like pregnancy or employment do influence the decision for cohabitation as well as its further development.
\end{abstract}


Contents:

1. Introduction

1.1 Background

1.2 Working assumptions

2. Data set and data preparation

3. The transition from being single to cohabiting

3.1 Descriptive statistics

3.2 Hazard analysis

3.2.1 Model and variables

3.2.2 Model results and discussion

4. Transitions following a first cohabitational relationship

4.1 Descriptive statistics

4.2 Hazard analysis

4.2.1 Model and variables

4.2.2 Model results and discussion

5. Conclusions

References

Appendix 


\section{Introduction}

Over the past years the formerly communist countries of Central and Eastern Europe have been receiving much attention by demographers, who study the rapid changes in fertility and nuptiality which have taken place in these countries during the 1990s (e.g. Philipov and Kohler 2001). Hungary is one of them. Over this period of time it has undergone profound political and economic changes which clearly had repercussions on the demographic behavior of its population (e.g. Kamaras 2003, Speder 2003). This country is of particular interest since demographic processes like the drop in the marriage rate, the rise in non-marital births, and the emergence of cohabitation have apparently set in already before the early 1990s. In this paper we concentrate on the formation of first unions among young Hungarian women. The formation of a first cohabitation and its further development is of particular interest to us. These developments include the transformation of the cohabitation into marriage vs. dissolution of the cohabitational union. The nature of our investigation is mostly descriptive in as far as we do not apply explicit theories in order to explain the behavior found. We rather intend to provide a careful description with a brief interpretation, and leave deeper explanation using various theoretical approaches to a later step.

The paper is structured in the following way: after a summary of recent demographic developments in Hungary we continue with the formulation of some working assumptions about the formation of cohabitational unions and their continuation or dissolution. The transition from being single to cohabiting and the possible transitions following union formation are treated separately in sections 3 and 4, respectively. Each section includes descriptive and multivariate analyses and is followed by a discussion of the results. Our conclusions are summarized in a final section.

\subsection{Background}

In figure 1 below we see the development of the female first marriage rate and the percentage of non-marital births between 1960 and 2001. It is clear that the decline in the rate of first marriage formation set in as early as 1980. By 2001 the rate 
was only half of what it used to be 40 years earlier. At the same time the share of nonmarital births started to increase after 1975, slowly at first, then at a much higher pace after 1990. The years 1990-2001 saw an increase in out-of-wedlock births by $78 \%$. Official calculations further show that in $200184 \%$ of those births were conceived by single women, while $14.5 \%$ of these children were born to divorced women (Council of Europe 2002).

\section{Figure 1:}

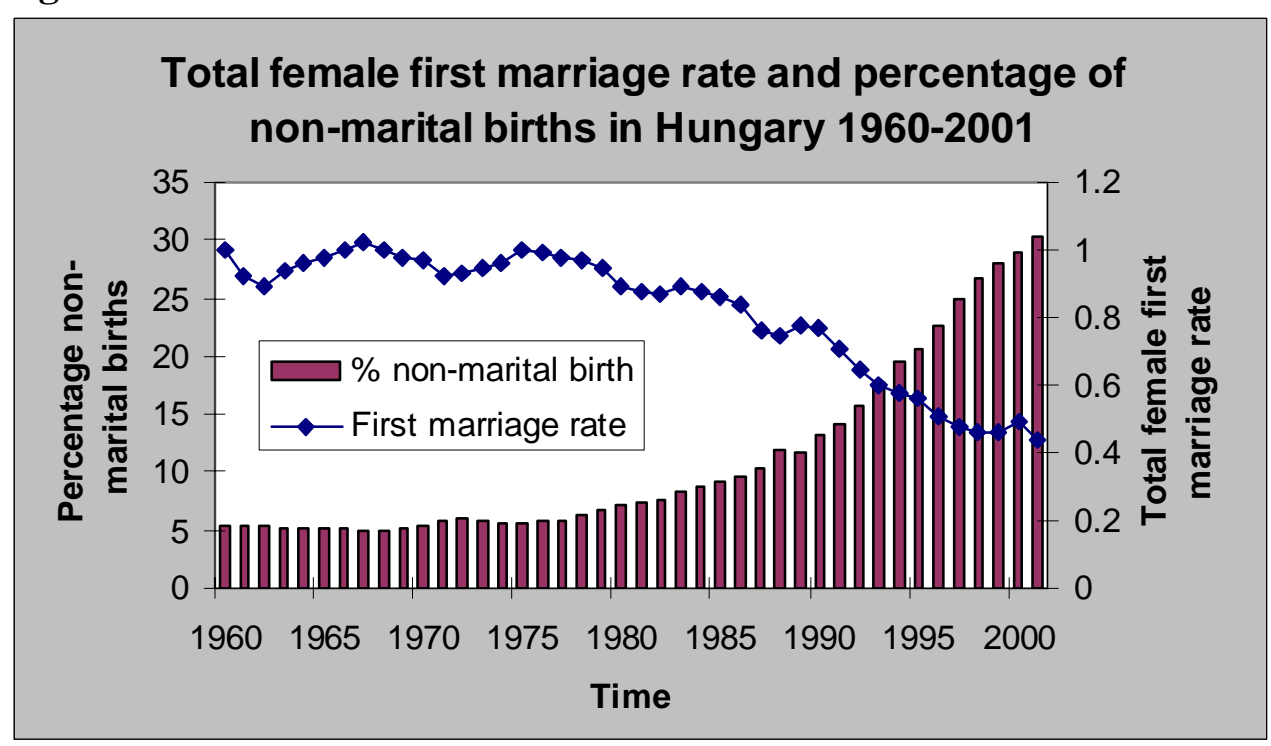

Source: Council of Europe, Demographic Yearbook 2002

We do not have access to longitudinal data on the occurrence of cohabitation in official statistics, but these two indicators suggest strongly that the share of cohabitants in the population must have increased considerably. According to Kamaras (2003) the percentage out-of-wedlock among the births in a given year is the closest estimate we can get of the fraction that cohabit among couples in the Hungarian population. Relying on this assumption we see a dramatic increase in cohabitation among young Hungarian adults, especially after 1990. Some of the few numbers available of those cohabiting in their early adulthood are summarized in Table 1 below.

Table 1: Percentages cohabiting among single women in Hungary

\begin{tabular}{|l|r|r|r|r|}
\hline \multicolumn{5}{|c|}{ Percentage of single women (15-29) cohabiting in selected years } \\
\hline Years & 1970 & 1984 & 1990 & 2001 \\
\cline { 2 - 5 } & 1.2 & 2.7 & 4.1 & 14.0 \\
\hline
\end{tabular}

Source: Speder (forthcoming) p. 82 
Evidently, the percentage who cohabit has increased dramatically after the onset of the transition period. Still, this choice of relationship could already be observed before 1990. Thus far, there has not been much in-depth research concerning such nonmarital unions and their stability (Speder forthcoming, Pongracz and Speder 2003). The sources listed include mostly descriptive statistics. Hence, until this time we have known very little about the development of these relationships and are left with several questions to answer and assumptions to examine. These will be formulated in the following section.

\subsection{Working assumptions}

As stated above we would like to study the emergence of cohabitation as a first union and the stability of such relationships. Are they rather transformed into marriage or do they end in dissolution? How long do Hungarian woman stay in these unions? What factors influence their choices?

Given the political and economic insecurity caused by the demise of the communist regime, we assume that unions (especially marriages) that would otherwise have been formed around this time, were delayed due to uncertainty concerning the future. Cohabitation, a less committing kind of relationship might seem more suitable to those involved, since this family form is more flexible while one adapts to the changing environment (Oppenheimer 1988). Furthermore, we also expect some ideational change within the population over time, a change that would make a nonmarital union an increasingly more accepted choice of living arrangement (Lesthaeghe and Surkyn 2002).

So, we can probably safely assume that the numbers who chose cohabitation over marriage should increase over the cohorts, reaching ever higher numbers at each age attained when compared to the preceding birth cohort. This should especially be true for those born after 1965, as those women lived through their early adulthood shortly before and during the transition period. Still, even if cohabitation becomes more prevalent, there could also be a postponement effect as young women might want to put off any union formation in times of economic and political turmoil. When we look at the subsequent development of these unions we would expect to see that it takes 
longer to transform a cohabitation into a marriage if the union began around the time of the societal transformation. Such behavior would also imply fewer marriages in total. At the same time we anticipate a rising risk of union dissolution as the partners must adjust to new demands of the labor force, like an increased demand for mobility. Also, more recent cohabitational relationships might not have been founded on the assumption of later conversion into marriage in the first place.

We believe moreover that different groups within the population will behave differently due to different individual characteristics, and due to varying experiences in life, and we would expect that these different factors interact with each other. Let us begin with pregnancy and childbirth, an aspect which is usually most closely intertwined with the decision to form a union. In Hungary marriage is still the predominant setting in which births occur. This leads us to suppose that a conception might not as easily induce single and childless women to enter cohabitation, instead those who notice conception should be more likely to marry directly. On the other hand, for those who already cohabit, a conception and the resulting childbirth should increase strongly the transition rate into subsequent marriage and at the same time reduce the risk of dissolution.

We now turn to variables that account for a woman's family background. We would expect a woman who has experienced that her parents divorced, to be more prone than other women to choose cohabitation over marriage because, for one, she has seen a marriage fall apart and secondly, she consequently, at least for some time, lived in a family which did not adhere to conservative norms. This experience should also make the woman less likely to marry once she has entered cohabitation. Additionally, a high number of siblings might result in a lack of financial resources within her family of origin so that a cohabitational relationship is likely (at least at first) to be preferred over a union which starts with a costly wedding. However, the experience of growing up in a large family might instill the desire to also have a family with many children. This family focus would rather result in (early) marriage than in a less committing cohabitation, so that the risk of the latter should be the smaller for women with many siblings. When it comes to religiousness we expect that when a woman believes in the teachings of the church this will decrease the attractiveness of cohabitation and increase the appeal of direct marriage or at least marriage formation after 
cohabitation. (See Manting 1996 for the influence of various individual characteristics on union formation.)

Finally, we turn to factors related to the economic capacity of an individual, namely educational attainment and labor force attachment. We believe that a person who is still actively involved in education will have a lower risk of entering any kind of committed union since she or he will want to devote time and attention to finishing education instead (Billari and Philipov 2003). We assume that this will be especially significant for the time after 1990 as an individual's human capital is much more important in a market economy than in one planned centrally where many choices were predetermined. A similar argument also applies to the effect of having taken up a job. Concerning a later transformation of a cohabitational union we suppose that those with a better economic outlook will also be more likely to turn their relationship into a marriage.

Since changes in macro patterns are the sum of changes on the micro level we need to look at modifications of individual behavior. In order to do so we cannot rely on aggregate level data but need data that contains individual information on each respondent. Information broken down in this way provides better insight into the dynamics of the changes, for example, whether the changes occur across all groups in the population or whether they only concern specific groups. The data set used for our empirical analyses is described in the following section.

\section{Data set and data preparation}

The empirical part of this research is based on the first wave of the Hungarian Gender and Generations Survey (GGS) ${ }^{1}$ carried out by the Demographic Research Institute of the Hungarian Central Statistical Office. The responses were collected between November 2001 and January 2002 among 8931 women and 7432 men between the ages of 18 and 75 . The data is especially suitable for our purposes as it includes full partnership histories (differentiating between marriage and cohabitation), fertility histories, and a series of variables that are assumed to influence partnership

\footnotetext{
${ }^{1}$ Officially known as "Turning Points of the Life Course" or "Hungarian Social and Demographic Panel Survey"
} 
and childbearing behavior, such as characteristics of the respondent's upbringing, some information on their education and employment careers, and so forth. The dataset allows for a detailed analysis over time, so that we are also able to study behavior before and after 1990. At this point we choose to only take the female part of the sample into account ${ }^{2}$. A similar analysis based on the male part of the sample should be just as interesting, but that must come later.

After the introduction of our working assumptions and the data used to explore them we now turn to the events under study. In section 3 we examine the transition from being single to a first cohabitation. We then turn to the transition of this cohabitational union to subsequent marriage vs. the dissolution of this relationship in section 4 . The multi-state diagram in figure 2 illustrates the transitions that are possible and those we are concerned with in our empirical analysis.

Figure 2: Possible transitions in the formation of a first union: those represented by bold arrows are included in the analysis; the ones represented by dotted arrows are left out $^{3}$

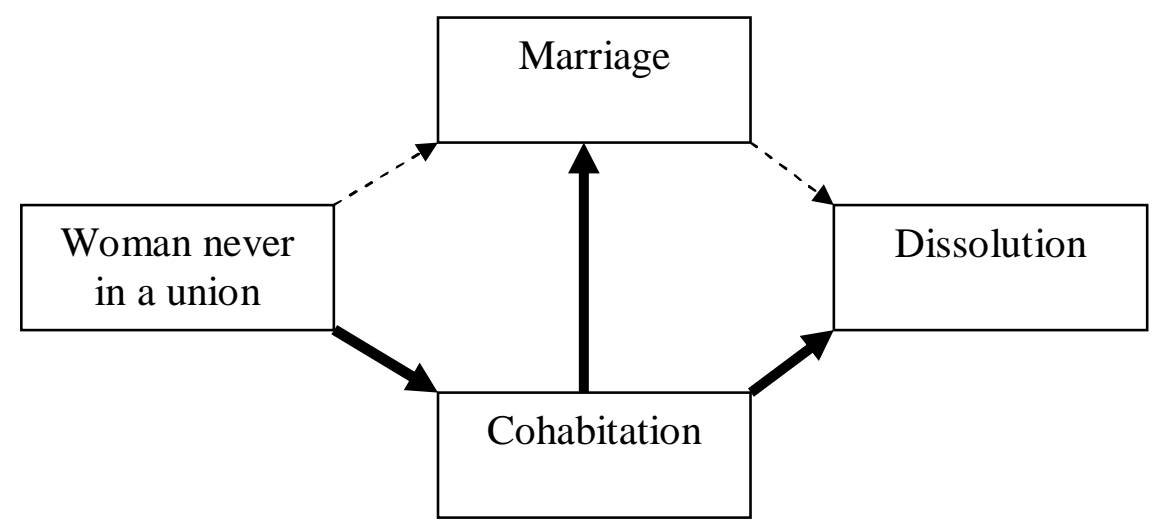

\footnotetext{
2 Additionally, before we put the data to its use it was adjusted according to the following considerations. Respondents of known Gypsy and Roma origin were excluded prior to analysis due to their small number and expected differing behavior. Members with this ethnicity also had a high nonresponse rate and possibly refused to admit their association with this group. Also excluded were women who experienced a conception, a first cohabitation or a first marriage before the age of 15, as they are likely to be a very select group. Further, the data was cleaned of respondents with missing dates on events crucial to our analysis (start of cohabitation, start of marriage, birthday of first child) and also of those cases where the first cohabiting union started after the month of interview. As interviews were carried out over several months the earliest possible month was taken as the date of censoring. The procedure is summarized in tables A1 and A2 included in our appendix.

${ }^{3}$ The transition from being single to direct marriage is also discussed briefly. We compare the impact of conception and childbirth on first direct marriage to their impact on first cohabitation.
} 


\section{The transition from being single to cohabiting}

As already outlined above, this section proceeds with some descriptive analyses of the transition to first cohabitation, followed by a hazard analysis based on an event history model.

\subsection{Descriptive statistics}

In this subsection we want to find answers to the question of how the process of forming a first cohabitation has changed over different birth cohorts of Hungarian women. The cumulative percentages of single women who formed a first non-marital relationship by a certain age, starting at age 15 , are displayed in table 2 . These results are based on life-table techniques ${ }^{4}$ illustrating a single decrement process. We see that with the exception of the two oldest cohorts, born as early as by WWII, the share of cohabiting women has increased cohort after cohort. Out of those born between 1976 and 1983 , as many as $35 \%$ started their union career by cohabitation by age 25 and so surpassed the cohort of their predecessors at age 30. There has also not been any clear sign of union postponement as we might have expected. Even at the youngest ages the proportions have clearly grown across cohorts. The increases are most visible for the two youngest cohorts, whose early adulthood took place shortly before or during the transition process.

Table 2: Cumulative percentages of women entering cohabitation

\begin{tabular}{|c|c|c|c|c|c|c|}
\hline \multicolumn{7}{|c|}{ Transition to a first cohabitation in \% by birth cohorts } \\
\hline Cohorts & $1926-35$ & $1936-45$ & $1946-55$ & $1956-65$ & $1966-75$ & $1976-83$ \\
\hline Ages & & & & & & \\
By age 20 & 0.88 & 0.27 & 1.81 & 4.88 & 12.57 & 16.34 \\
By age25 & 1.28 & 1.02 & 3.21 & 9.29 & 24.84 & 34.94 \\
By age 30 & 1.72 & 1.75 & 4.32 & 11.14 & 30.18 & $*$ \\
\hline
\end{tabular}

Source: own calculations based on GGS data (2001)

* No events due to young ages at interview

\footnotetext{
${ }^{4}$ Kaplan-Meier survival functions (Kaplan and Meier 1958)
} 
As pointed out earlier, we also expect women's experiences to differ before 1990 and afterwards, and also during these time periods. Further, we also assume that different groups within the population will have different risks of selecting themselves into cohabitation due to varying individual characteristics like family background, religiousness, the arrival of a first child, educational activity or labor force attachment. Such factors reflect changes in socialization, as well as ideational and structural changes. Hence, in a continuation of the results above, the empirical analysis to follow will account for such expected variations.

\subsection{Hazard analysis}

The methodological tool here is event history analysis ${ }^{5}$ in the form of a proportional hazard model with a piece-wise linear baseline spline. Compared to the non-parametric approach above it has the advantage that it can cope with several explanatory variables and allows to control for several dimensions of time like period, age or the duration since a particular point in time. For the estimation of our models we use a multilevel multiprocess statistical software (aML) introduced by Lillard and Panis (2003).

\subsubsection{Model and variables}

Our hazard function for the risk of transition to a first cohabitation, given a vector of covariates which influence it, is defined as follows:

$\ln h_{i}(t)=y(t)+\Sigma \alpha_{j} x_{i j}+\Sigma \beta_{j} w_{i j}(t)+c\left(t-u_{i}\right)$

where $\ln h_{i}(t)$ is the log hazard rate of first cohabitation for an individual $i$ at a given time $t$, with the months of exposure to the risk starting on the $15^{\text {th }}$ birthday of each respondent and ending on her $35^{\text {th }}$ birthday ${ }^{6}$. Furthermore, $y(t)$, a piece-wise linear spline represents the baseline log intensity. It captures the influence of the basic

\footnotetext{
${ }_{6}^{5}$ also known as Survival Analysis or Failure Time Data Analysis

${ }^{6}$ After this age there are very few events of first union formation or first childbirth.
} 
duration (current age) on the intensity (first cohabitation). The model also includes a set of time-fixed covariates which are symbolized by $x_{i j}$ with parameters $\alpha_{j}$ which measures their impacts. There are also some time-varying factors represented by $\beta_{j} w_{i j}(t)$. Finally, a duration spline accounting for conception and childbirth is added, $c\left(t-u_{i}\right)$, kicking in at the time $u_{i}$ of the occurrence of conception. The spline is a continuous function of time $t$, back-dated 9 months from the birth of a first child ${ }^{7}$. The process time ends at the formation of a first cohabitation. A case is right-censored if a woman marries directly or when she reaches age 35 . If neither of the events occurs the date of interview ends the process time. The calendar period considered stretches from January 1941 until October 2001, which is the time between when the first respondents reach age 15 and the time of the first interviews. It is important to point out that the data set has been divided into two parts. The first part covers all episodes during the time until the end of 1989 at which point the data is right-censored. The second part of the data includes all episodes from January 1990 on until the time of interview. This results in left-censoring of this particular portion of the data.

We now turn to the description of the covariates. As noted above our basic duration spline accounts for the effect of age on the transition to a first cohabitational union. In addition to the partitioning of the data we enter a further subdivision of the time periods within the two models in order to allow for a more detailed view of the development over time. As we already saw in the descriptive analysis (section 3.1) changes set in already before 1990 .

We express the influence of a conception and subsequent childbirth by a conditional spline as defined above. Accounting for the influence of childbirth over time, including the time of pregnancy, must be appropriate since many decisions which concern union formation are taken prior to birth and also seem to vary during this period of time.

In order to account for the effects of a respondent's upbringing we include a variable controlling whether the woman experienced the divorce of her parents until age 15 . In

\footnotetext{
${ }^{7}$ Before taking a final decision on how to treat the influence of birth so as to display the effect of pregnancy and birth most clearly we tested two different options. We first backdated the birth by eight months and simultaneously included an intercept to account for possible initial effects when a woman realizes that she is pregnant. In our final version however, as the other variation did not provide any additional information, we settled for subtracting nine months from the date of birth and including a node two months into pregnancy, at birth and six months after birth. In the models estimating transitions to direct marriage and marriage after cohabitation we included an additional node six months into pregnancy in order to obtain more differentiated results.
} 
addition to it we include the number of siblings as a covariate as well as a question about the respondent's religiosity. The fact that the latter information is only available at the time of interview might constitute a problem as the views might change between age 15 and the date of interview. However, we presume that after this age this particular opinion has been established to a sufficient degree as to take it as a time-constant value.

We finish with factors related to the economic capacity of an individual, educational attainment and labor force attachment. In order to control for educational activity we include a variable indicating whether a woman is (still) in education or not, rather than differentiating women by their final level of education ${ }^{8}$. In the case of Hungary we assume that the concept of "life-long learning" has not been popular until now, so that once a woman leaves education she does not go back to continue it at a later point in time. The last covariate taken into account is the fact whether a woman has taken up regular paid work. Just like educational activity and period this is a time-varying variable, whereas the remaining ones stay constant over time.

\subsubsection{Model results and discussion}

We now display the results of our full event history model, beginning with the baseline intensity according to a woman's age. The intensity is shown in figure 3, where we differentiate between the two period-models. We show the effect of age only as well as its standardized influence. It results when we include all factors, and produces a proportional shift of the baseline. We see that once individual characteristics of women are controlled for, there is hardly a difference in the intensity of forming a cohabitation over age during the two time periods. This implies that the factors included in the analysis do account for the differences between the time before and after transition.

\footnotetext{
${ }^{8}$ In order to avoid anticipatory analysis we chose controlling for educational activity rather than level, as detailed educational histories will only be available in the second wave of the GGS. We also believe that finishing education itself might have a more significant impact than just reaching a particular level of it.
} 
Figure 3:

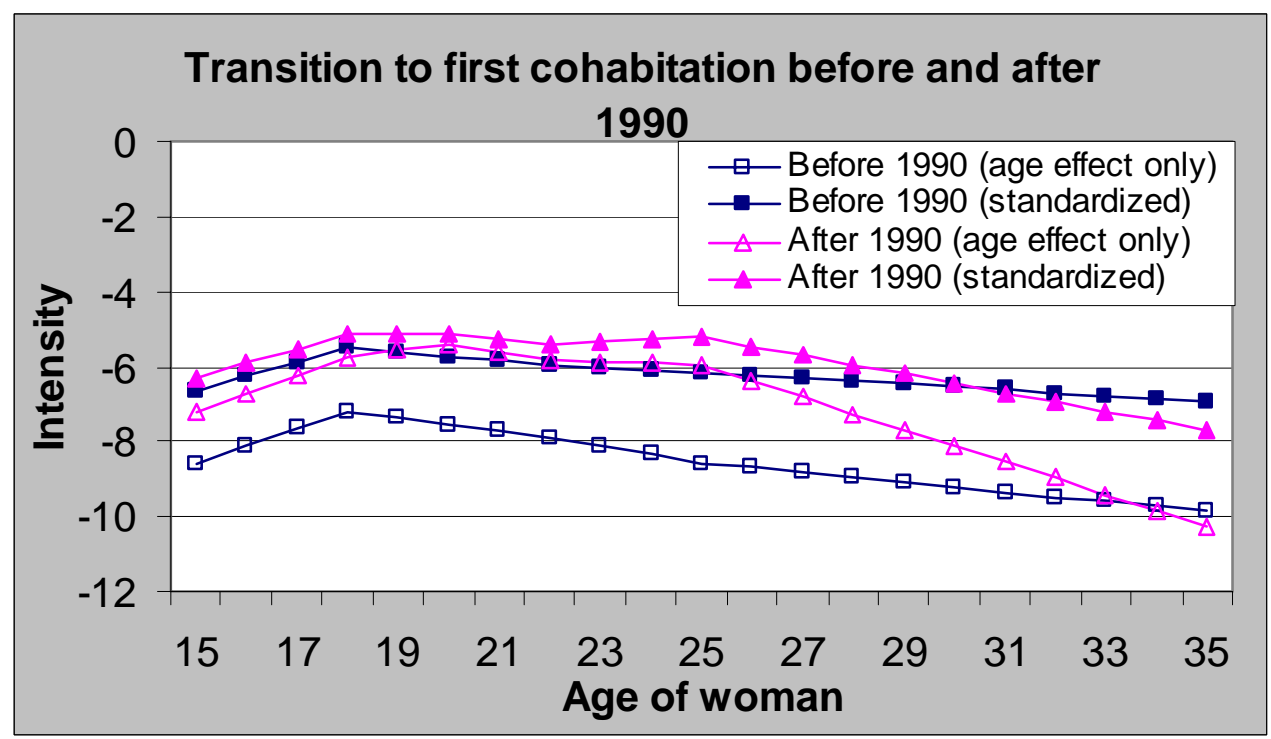

Source: own calculations based on GGS data (2001)

As we can see in the figure, the rates of transition into cohabitation accounting for age only were clearly higher during the period after 1990 when compared to the time before. The two intensities only reach a similar level beyond age 30, which might be partly due to a low number of events at that age. The peak is reached at age 18 during the time before transition which points towards more of an early and age-determined move into cohabitation, while there is more of a constantly high intensity between the ages of 18 and 21 for the time after 1990. The age is moving out and indicates slight postponement in the formation of first cohabitations, possibly of first unions in general during the later period.

Figure 4 depicts the influence of pregnancy and childbirth on the transition under study. As mentioned above, a pregnancy is backdated by nine months from the child's date of birth, and its effect is observed in the portion of the figure where the $\mathrm{x}$-axis is labeled -9 to 0 . We see that before 1990 a pregnancy and birth clearly discouraged the formation of a first cohabitation. The event remained neutral only during the first two months of pregnancy, while the woman possibly was not yet aware of the conception. After the onset of the transition period, on the other hand, the risk of non-marital union formation increases during a first pregnancy and remains above its initial level until the birth of the child. Thereafter the risk decreases strikingly and even falls below its level in the earlier period. A possible interpretation could be that before 1990 the norm was to bear one's children almost exclusively within marriage. Thus single women who realized that they were pregnant, would much rather get married to 
their partners than begin a non-marital union. During the transition period this norm may have been relaxed so that it now is the union itself which remains important for bearing a child and not its character. But what we also see is that if a union has not started during pregnancy, the mother is very likely to remain single.

Figure 4:

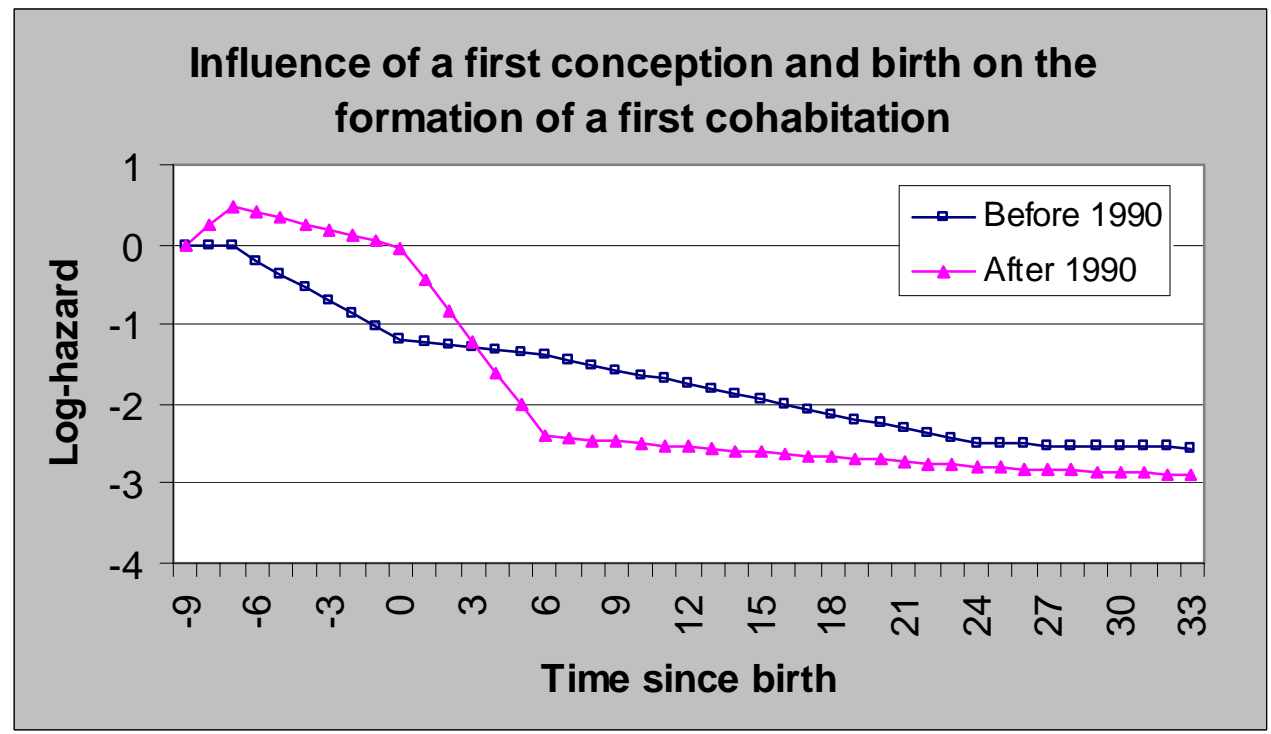

Source: own calculations based on GGS data (2001)

In order to examine whether our above interpretation of the influence of conception and childbirth on union formation is correct, we also investigate the influence of pregnancy and birth on the risk of forming a first direct marriage. The results in figure 5 confirm our expectations. A single woman who becomes pregnant is most likely to choose direct marriage over cohabitation. This is obviously true for the time before as well as the time after 1990. Women usually marry during the first two trimesters of their pregnancy and the log-hazard drops sharply afterwards. Nevertheless, this transition was much the smoother during communist times. A woman tends to marry during early pregnancy or else not marry at all in post-communist times. While there seems to be a growing group of women who choose cohabitation, at the same time those who remain more conservative and choose marriage as the context for childbearing clearly do so before the child is born. There seems to be a growing behavioral difference between these two groups of women. After this short discourse we now turn back to our analysis of non-marital relationships.

Figure 5: 


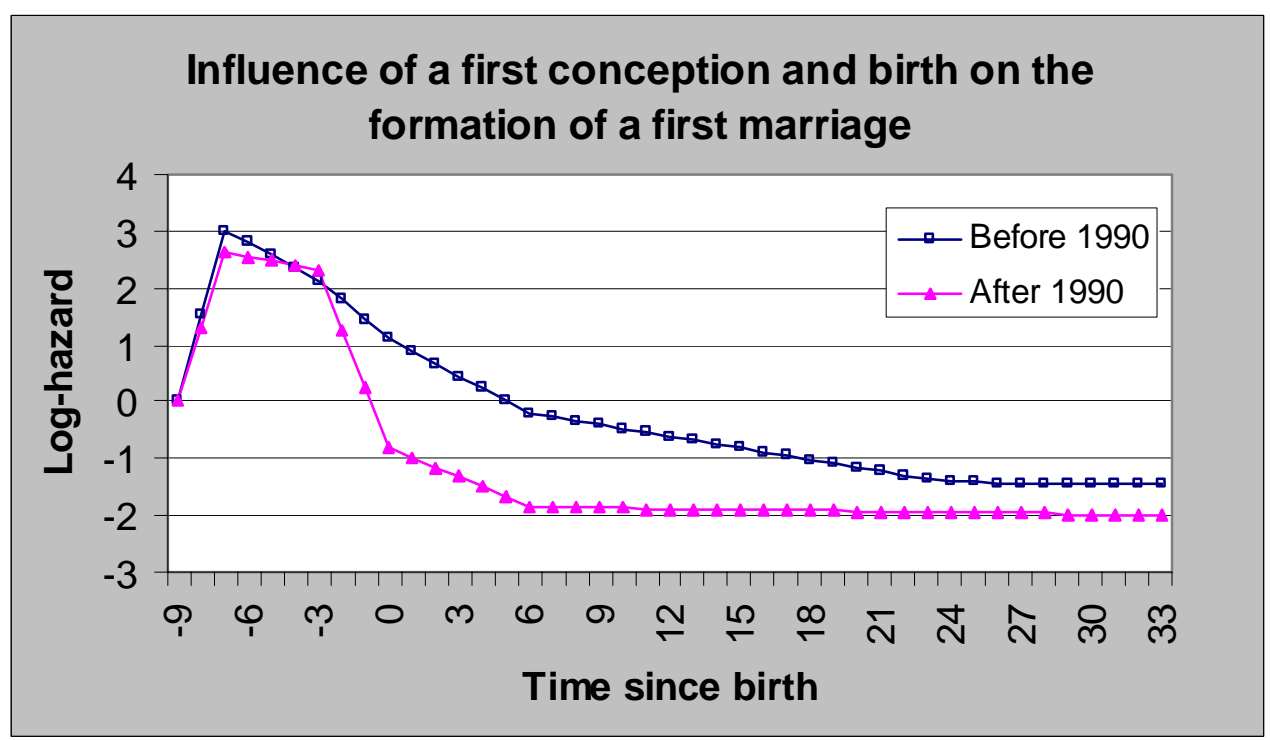

Source: own calculations based on GGS data (2001)

We focus on the results of our multivariate model. We discussed the influence of age and pregnancy above, and now continue with a more detailed look at the time before and after 1990 (Table 3). We find significant differences within the two time periods. The relative risks clearly increase from period to period. This reveals an ongoing increase in first cohabitational unions after 1990. These results are in accordance with our previous descriptive analysis, which therefore caught the main traits of developments.

Most of the variables which control for the respondent's socialization also point in the expected direction. The relative risk to form a cohabitation is about $80 \%$ higher among women who experienced parental divorce. Even though it is somewhat smaller during the later time period, the risk remains highly significant. Those who do not follow the teachings of the church are more likely to cohabit than those who do not. This is not surprising as those who are more religious are usually also more prone to choose a more traditional and conservative form of partnership. What is striking is that this division becomes even more significant after the onset of the transition. This could mean that while a growing number of people see cohabitation as a suitable option, their religious belief also matter more after a time during which religiousness was suppressed. Unfortunately, the effect of the number of one's siblings on this choice of union does not give a clear lead toward any one of the assumptions stated above.

Finishing education markedly increases a woman's risk to commit to a non-marital relationship. There is hardly any difference over time in the relative risk; we expected 
a stronger impact during the time of the transition. We can see such an increase in impact for our final variable of the model. A woman who has taken up a regular job, has much the higher risk of entering cohabitation, and even more so in the later time period. This finding confirms our assumption that a position in the labor force becomes more important after 1990. 
Table 3: Full model of the transition from being single to cohabiting

\begin{tabular}{|c|c|c|c|c|c|c|c|c|}
\hline reference $=$ most cases & $\begin{array}{l}\text { BEFOR } \\
\text { b }\end{array}$ & $\begin{array}{l}1990 \\
\exp \\
\text { (b) }\end{array}$ & SE & & $\begin{array}{l}\text { AFTER } \\
\text { b }\end{array}$ & $\begin{array}{l}990 \\
\exp \\
\text { (b) }\end{array}$ & SE & \\
\hline Baseline (woman's age): & & & & & & & & \\
\hline Intercept/Constant & -6.69 & & 0.27 & $\star * \star$ & -6.30 & & 0.27 & *** \\
\hline Slopes between ages: & & & & & & & & \\
\hline $15-18$ & 0.03 & & 0.01 & $* * *$ & 0.03 & & 0.01 & $* * *$ \\
\hline $18-20$ & -0.01 & & 0.01 & & 0.00 & & 0.01 & \\
\hline $20-22$ & -0.01 & & 0.01 & & -0.01 & & 0.01 & * \\
\hline $22-25$ & -0.01 & & 0.01 & & 0.01 & & 0.01 & \\
\hline $25-35$ & -0.01 & & 0.00 & * & -0.02 & & 0.00 & *** \\
\hline $\begin{array}{l}\text { Pregnancy and birth of first } \\
\text { child: } \\
\text { Start of pregnancy (backdated } 9 \text { months } \\
\text { from birth) } \\
\text { Slopes between months: }\end{array}$ & & & & & & & & \\
\hline Pregnant $0-2$ months & -0.01 & & 0.18 & & 0.24 & & 0.15 & \\
\hline Pregnant 3-9 months & -0.17 & & 0.10 & * & -0.07 & & -0.07 & \\
\hline Birth - 6 months & -0.03 & & 0.13 & & -0.40 & & 0.13 & *** \\
\hline 7 months- 2 years & -0.06 & & 0.03 & * & -0.02 & & 0.05 & \\
\hline Older than 2 years & -0.01 & & 0.00 & & -0.01 & & 0.01 & \\
\hline $\begin{array}{l}\text { Periods: } \\
\text { before: }\end{array}$ & & & & & & & & \\
\hline $1941-59$ & -2.87 & 0.06 & 0.24 & 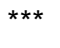 & & & & \\
\hline $1960-69$ & -2.12 & 0.12 & 0.18 & $\star * *$ & & & & \\
\hline 1970-79 & -1.23 & 0.29 & 0.13 & $* * *$ & 0 & 1 & & \\
\hline 1980-89 & 0 & 1 & & & 0.35 & 1.43 & 0.08 & *** \\
\hline $\begin{array}{l}\text { (Childhood) background: } \\
\text { Parental divorce until age } 15 \text { (included) } \\
\text { no }\end{array}$ & 0 & 1 & & & 0 & 1 & & \\
\hline $\begin{array}{l}\text { yes } \\
\text { Number of siblings }\end{array}$ & 0.58 & 1.79 & 0.15 & *** & 0.46 & 1.59 & 0.10 & *** \\
\hline 0 & -0.18 & 0.83 & 0.16 & & -0.27 & 0.76 & 0.13 & ** \\
\hline 1 & 0 & 1 & & & 0 & 1 & & \\
\hline $\begin{array}{l}2 \text { or more } \\
\text { Religiousness }\end{array}$ & -0.41 & 0.67 & 0.12 & *** & -0.23 & 0.79 & 0.09 & *** \\
\hline Following teachings of church & -0.32 & 0.73 & 0.16 & * & -0.51 & 0.60 & 0.14 & *** \\
\hline Not (really) following teachings of church & 0 & 1 & & & 0 & 1 & & \\
\hline $\begin{array}{l}\text { Education: } \\
\text { Educational activity }\end{array}$ & & & & & & & & \\
\hline Not anymore in education & 0 & 1 & & & 0 & 1 & & \\
\hline Still in education & -0.51 & 0.60 & 0.12 & $\star * \star$ & -0.43 & 0.65 & 0.09 & *** \\
\hline $\begin{array}{l}\text { Employment: } \\
\text { Has taken up regular paid work }\end{array}$ & & 1 & & & 0 & 1 & & \\
\hline Has not taken up regular paid work & -0.15 & 0.86 & 0.14 & & -0.42 & 0.66 & 0.10 & *** \\
\hline
\end{tabular}

Source: own calculations based on GGS data (2001)

Significance: $*=10 \%, * *=5 \%, * * * 1 \%$ 


\section{Transitions following a first cohabitational relationship}

The increasing numbers of young Hungarians who begin their relationship career by cohabitation, and the falling rate of first marriage, show a clear trend away from traditional partnership forms. However, this development does not mean that marriage has been superseded. It can also take place after an initial period of cohabitation. Therefore, we are interested in what becomes of cohabitational unions. Just as we investigated the peculiarities of the transition to first cohabitation we will now turn to a similar investigation of its stability. Section 4 focuses on the question whether these relationships are subsequently transformed into marriages or whether the partners split up. We also want to analyze the changes over time and take into account individual characteristics which might lead to different behavior among the women in our sample.

\subsection{Descriptive statistics}

Similar to the approach in section 3.1 we begin with some descriptive analyses of what happens with cohabitations, distinguishing between birth cohorts ${ }^{9}$ and timecohorts during which the initial relationship began. While we again calculate the cumulative percentages of those who transform their non-marital relationship in a given way, we now do it according to the duration of the union, starting at its beginning. The technique itself remains the same as in section 3.1.

We see that most first relationships which started by cohabitation are turned into a subsequent marriage rather than end in dissolution, while almost just as may women have remained in that relationship up to the time of interview (table 4).

\footnotetext{
${ }^{9}$ In contrast to previous analyses, we now combine the older cohorts to form one cohort of women born between 1926 and 1955. We did so because of the small number of events among the women born during these years.
} 
Table 4: Transitions out of cohabitation

\begin{tabular}{|l|rrrr|}
\hline & $\begin{array}{r}\text { Subsequent } \\
\text { marriage }\end{array}$ & $\begin{array}{c}\text { Dissolution } \\
\text { of } \\
\text { cohabitation }\end{array}$ & in 2001 & \\
\hline All & & & & \\
cohabitations & 500 & 291 & 275 & 1066 \\
Percentages & 47 & 27 & 26 & 100 \\
\hline
\end{tabular}

Source: own calculations based on GGS data (2001)

Table 5 illustrates in more detail that even though the majority of cohabitational relationships is still turned into marriage, the percentage of those finally doing so has been decreasing over cohorts. Also, the decision to tie the knot is taken after an increasingly longer duration of the cohabitational union. A similar development can be observed when we divide our sample by the calendar period in which the initial relationship began.

Table 5: Cumulative percentage of women entering marriage after cohabitation

\begin{tabular}{|c|c|c|c|c|c|c|c|c|}
\hline \multirow[b]{2}{*}{ Duration } & \multicolumn{4}{|c|}{ By birth cohort } & \multicolumn{4}{|c|}{$\begin{array}{l}\text { By starting year of } \\
\text { cohabitation }\end{array}$} \\
\hline & $1926-55$ & $1956-65$ & $1966-75$ & $1976-83$ & $1945-80$ & $1981-90$ & 1991-95 & 1996-01 \\
\hline 1 year & 34.96 & 36.62 & 24.97 & 12.66 & 41.49 & 31.84 & 23.3 & 12.76 \\
\hline 2 years & 42.57 & 49.95 & 36.66 & 20.83 & 53.73 & 43.7 & 32.69 & 21.91 \\
\hline 4 years & 48.87 & 56.44 & 45.04 & 28.17 & 57.96 & 52.08 & 42.58 & 28.35 \\
\hline 6 years & 52.74 & 61.45 & 49.55 & 36.44 & 61.29 & 57.05 & 48.42 & * \\
\hline
\end{tabular}

Source: own calculations based on GGS data (2001)

* No events due to young ages at interview

In table 6 we see the other side of the development of cohabitational unions. While the share of those who turn their union into a marriage has been decreasing, the percentage of those cohabitations that end in dissolution has been increasing. Still, the subdivision by calendar period of union formation shows that the rise in dissolutions only took off for those unions established after 1990. 
Table 6: Cumulative percentage of women ending cohabitation by dissolution

\begin{tabular}{|c|cccc|cccc|}
\hline \multicolumn{1}{|l|}{$\begin{array}{l}\text { Transition from a first cohabitation to the dissolution of that cohabitation in \% by cohort and } \\
\text { starting years }\end{array}$} \\
\hline & By birth cohort & & & \multicolumn{3}{l|}{$\begin{array}{l}\text { By starting year of } \\
\text { cohabitation }\end{array}$} \\
\hline Duration & $1926-55$ & $1956-65$ & $1966-75$ & $1976-83$ & $1945-80$ & $1981-90$ & $1991-95$ & $1996-01$ \\
\hline & & & & & & & & \\
1 year & 7.16 & 5.8 & 8.38 & 14.63 & 6.33 & 4.81 & 9.01 & 14.95 \\
2 years & 13.55 & 8.29 & 14.73 & 22.52 & 11.62 & 8.27 & 15.07 & 23.88 \\
4 years & 17.66 & 14.62 & 21.07 & 36.95 & 15.85 & 13.88 & 21.96 & 38.23 \\
6 years & 20.68 & 16.51 & 26.19 & 40.37 & 18.66 & 18.84 & 25.41 & $*$ \\
\hline
\end{tabular}

Source: own calculations based on GGS data (2001)

* No events due to young ages at interview

Once again we will now test the influence of individual characteristics on the two possible transitions out of cohabitation.

\subsection{Hazard analysis}

As in section 3.2 the methodological tool to do so is event history analysis in the form of a proportional hazard model with a piece-wise linear baseline spline. Compared to the non-parametric approach above it has the advantage that it can cope with several explanatory variables and also allows to control for several dimensions of time like period, age or the duration since a particular point in time.

\subsubsection{Model and variables}

For the analysis of the possible transitions following cohabitational formation we carry out a competing risks analysis with two hazard functions, as there are two possible transitions that can result from the initial union which "compete" with each other for their occurrence. As soon as one of them takes place the woman is not anymore exposed to the risk of experiencing the other. The first stands for the risk of transition to a subsequent marriage, the other for the risk of disruption of the cohabitational union. Each function, again, includes a vector of covariates which influences it and is defined as follows: 
$\ln d_{i}(t)=y_{d}(t)+\sum \alpha_{j d} x_{i j}+\sum \beta_{j d} w_{i j}(t)+c_{d}\left(t-u_{i d}\right)$

and

$\ln \mu_{i}(t)=y_{\mu}(t)+\Sigma \alpha_{j \mu} x_{i j}+\Sigma \beta_{j \mu} w_{i j}(t)+z_{\mu}\left(t-v_{i \mu}\right)$

where $\ln d_{i}(t)$ and $\ln \mu_{i}(t)$ are the respective $\log$ hazard rates of each event for an individual $i$ at a given time $t$, with the months of exposure to the risk starting with the formation of the cohabitation and ending ten years later ${ }^{10}$. Furthermore, $y_{d}(t)$ and $y_{\mu}(t)$ are two piece-wise linear splines that represent the baseline log intensities. They capture the influence of the basic duration (duration of cohabitation) on the particular intensity (subsequent marriage or disruption). The models also include a set of timefixed and time-varying covariates which are common to both processes but have different parameters $\alpha_{d}, \alpha_{\mu}$ and $\beta_{d}, \beta_{\mu}$. See section 3.2.1 for more details of the equations. The process time ends at the formation of a subsequent marriage or the split of the cohabitation, respectively. A case is right-censored if a woman chooses a marriage when we study the intensity of dissolution (and consequently vice versa for the marriage intensity), or when the initial union has lasted for ten years. If neither event occurs the date of interview ends the process time. This time we do not partition our data set as this is likely to result in too few cases in the different categories of the factors included in our model.

Now that we have established the form of our model in which two risks compete with each other, we turn to a brief summary of the covariates it includes. The basic duration splines now account for the effect of union duration instead of controlling for current age, so that we include the latter as a separate covariate. Further, we do not attempt a separate analysis of the time before and after 1990. Instead we enter the year in which the initial union began as a fixed covariate in the analysis.

The remaining covariates account for childhood experiences as well as education and employment; they remain the same as in the previous model in section 3.2. We now turn to our results.

\footnotetext{
${ }^{10}$ After a duration of ten years there are very few cohabiting unions left and very few transitions, respectively.
} 


\subsubsection{Model results and discussion}

The baseline intensity according to the duration of the non-marital union (figure 6) shows that when we do not control for influences other than union duration, the intensity of a subsequent marriage is clearly higher than that of partnership dissolution. Once other factors are included the two intensities do not differ much. The only marked variation can be observed during the first six months of the union. During this time the intensity of a subsequent marriage is much higher than that of a split. This seems plausible as it is during a period when the initial decision to form a union was just taken. Then, after they have remained at a high level for another six months both intensities decrease until two years into the union and then stay at a constantly low level. Obviously most of the decisions to transform a cohabitation are taken within the first twelve months of its duration.

\section{Figure 6:}

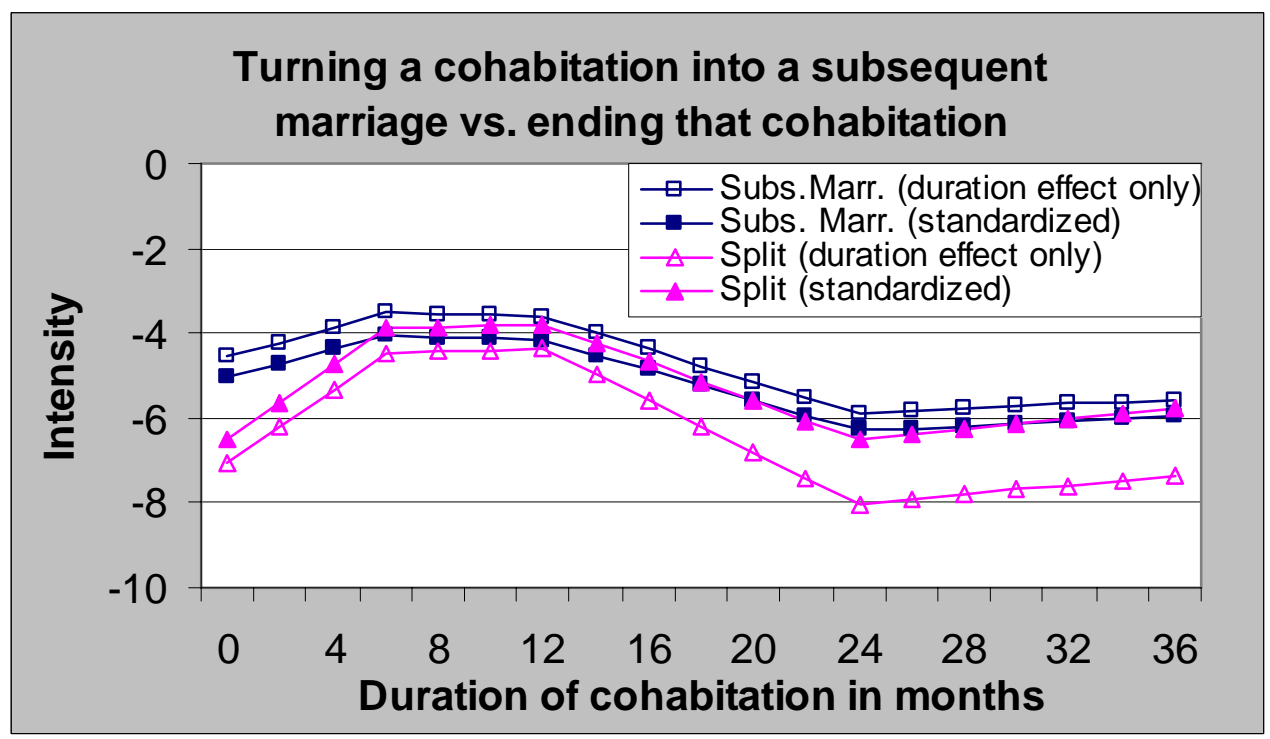

Source: own calculations based on GGS data (2001)

Pregnancy and childbirth, as shown in figure 7, clearly have more of an influence on the subsequent development of a cohabitational union than on its initial beginning. When conception occurs within cohabitation it significantly increases the risk of a subsequent marriage while the woman is still pregnant. It is highest at about six months into pregnancy and thereafter it falls to its original level. Once the child is three months old and marriage has not occurred, the risk decreases slightly below what it was before conception. When we observe the influence of conception and 
childbirth on a split of the partners we see that its risk decreases during the first two months of pregnancy and then rises again until the time of birth. After that it falls again and remains at a level constantly lower than before conception. While the risk of a subsequent marriage decreases if the woman does not marry her partner up until a certain time after childbirth, the risk of a split is constantly lower than before childbearing. In this case, the partners possibly leave their union status unchanged.

Figure 7:

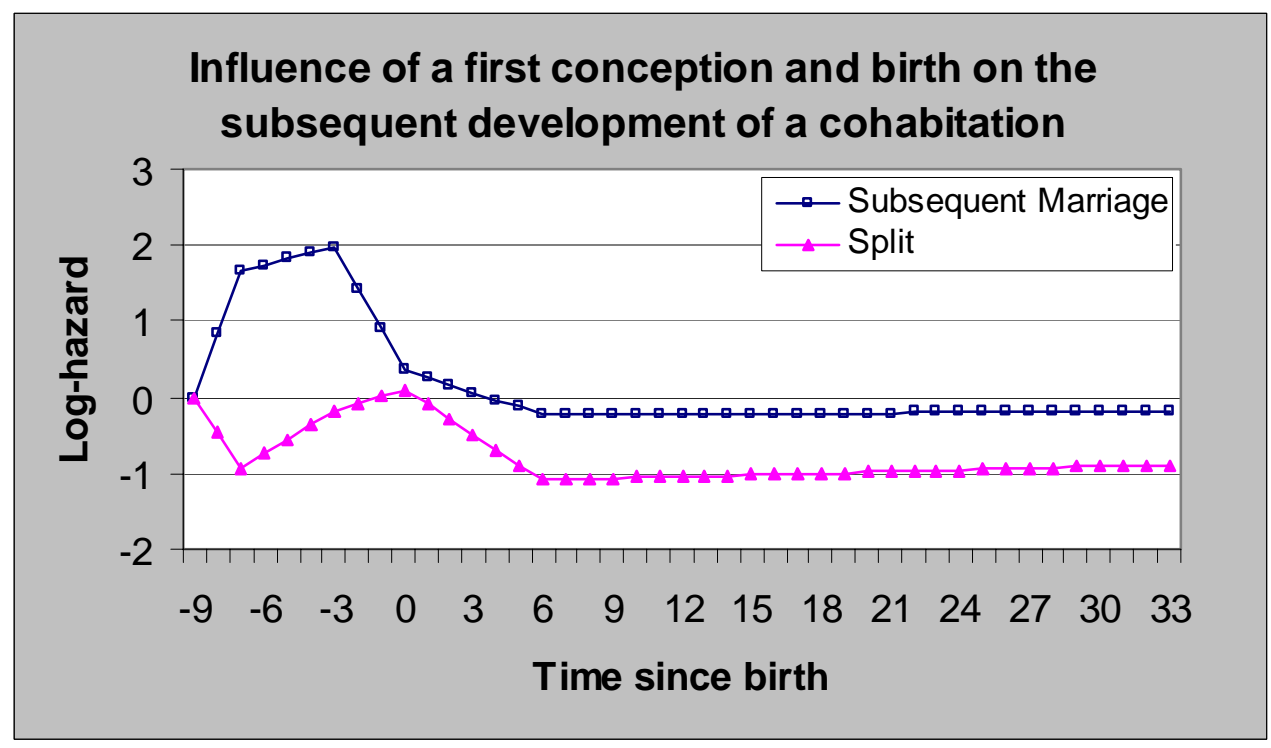

Source: own calculations based on GGS data (2001)

We now turn to the discussion of our final empirical results of the multivariate model shown in table 7. The variable that controls for a woman's age at start of cohabitation indicates that the relative risk of subsequently getting married is lowest for those who start their first relationship above age 25. This is understandable as these women seem to be a select group who started their union career relatively late and so might not have been inclined to form committed relationships in the first place. The risk of dissolution is highest for women who were relatively young when they entered the union, though the differences by age at union formation are not statistically significant. Obviously, young women are less likely to commit to their partners if their union begins at an early age. Our indicator for the success of a cohabitational union, according to the time period in which it began, ${ }^{11}$ shows that the relative risk of a subsequent marriage has been decreasing over time. Those who started cohabiting

\footnotetext{
${ }^{11}$ Due to a small number of occurrences of the respective event up to 1990 , we were not able to further subdivide the category that includes the years 1945 through 1990.
} 
before societal transition have a risk almost twice as high to turn their union into a marriage as those who started it in the second half of the 1990s. What is striking is that there is not only a difference between the time before and after 1990, but that there is continuing change during the transition period. When we turn to the risk of dissolution we see that, surprisingly, it only changed during the second half on the 1990s. It seems that even though cohabitation has been spreading, it was more of a "trial marriage" until that time and that much less of the unions were ending in dissolution.

The variables entered in order to pick up patterns caused by a respondent's early life experiences point in the expected directions, albeit not in a statistically significant manner. Educational activity, though its effect points in the direction anticipated, is also insignificant whereas it was highly so in the previous model. Clearly, it has much more of an impact on the initial decision to form a union than on its later bearing. The fact of not having taken up a job considerably increases the relative risk of union dissolution. This finding leads us to conclude that women without a certain economic basis are less likely to be in a stable relationship. 
Table 7: Full model of the transitions following a first cohabitation

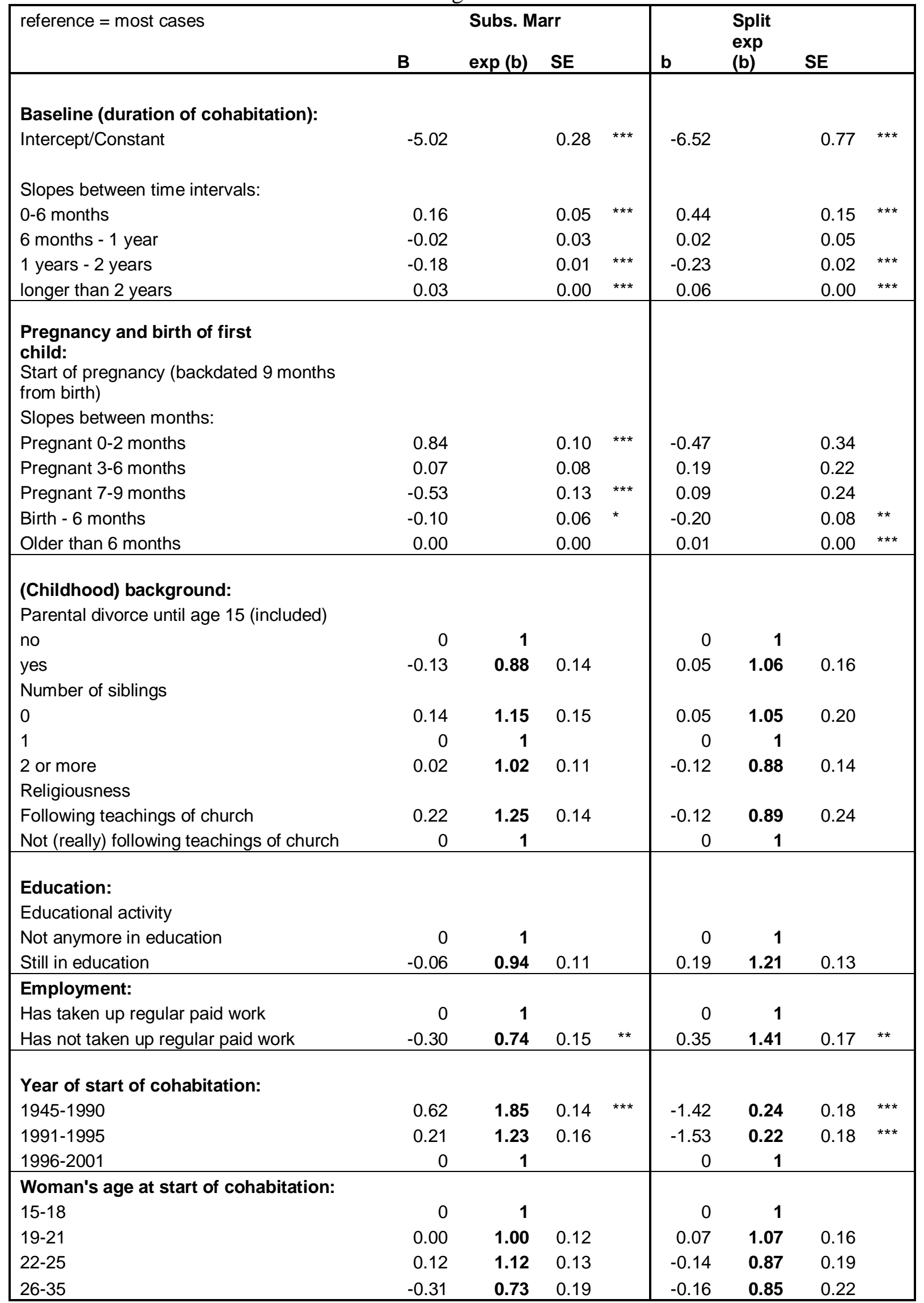

Source: own calculations based on GGS data (2001)

Significance: $*=10 \%, * *=5 \%, * * * 1 \%$ 


\section{Conclusions}

After completion of our analysis we can conclude that cohabitation as a first relationship started to emerge already before the onset of the societal transformation beginning in 1990. However, it did not gain momentum until the time of transition. Our analysis further shows that most cohabitations are still transformed subsequently into marital unions and that the marked increase in dissolutions did not set in until the second half of the 1990s.

Our hazard analysis demonstrates only a slight delay of the age at which cohabitations begin. This proves our assumption that cohabitation is a form of relationship which might be preferred over direct marriage, especially in times of social and economic uncertainty. While the mean age at first marriage has been increasing steadily, the age at first cohabitation has not. Furthermore, this confirms the cohabitation's function as a trial marriage during which one does not want to commit entirely, either for personal reasons or because of economic insecurity. The fact that cohabitational unions are also increasingly longer in duration causes a delay of subsequent marriages, which reinforces the higher ages at first marriage. Due to such interrelationships and because of the very different effects of pregnancy and childbirth on both kinds of first unions, the two transitions are crucial parts of the same picture explaining first union formation. Because of this the transition to a first direct marriage should and will be included in later stages of our research to ensure that no important factors are left out in the examination.

As far as ideational changes are concerned religiousness seems to play an even bigger role in the choice to enter a cohabitational union nowadays than it did before the societal transition. This might be surprising in the context of Western European countries, but in some Eastern European countries religion only had a chance to gain in significance after the demise of communism. Another finding that is unexpected because it reveals a group of women who exhibit seemingly more conservative behavior after 1990 is the influence of pregnancy on direct marriage formation. It seems that those who choose direct marriage over cohabitation when the woman becomes pregnant also make sure that the marriage takes place as quickly as possible. This in turn indicates a division between the growing number of those who are more likely to approve of non-traditional family forms and those who remain or are becoming even more conservative in this behavior. 
Finally, we were also able to show the growing importance of economic independence on the formation of a consensual union and its later stability. In order to get a more detailed picture of the former development, later research should include some analyses in which individuals are also subdivided by educational levels or according to socio-economic status. 


\section{References}

Billari F. and Philipov, D. (2003). Mutual relationships between education and women's entry into a first union: the case of Central and Eastern Europe. Population of Central and Eastern Europe: Challenges and Opportunities, Kotowska, E. and Jozwiak, J. (eds.). 2003, Warsaw.

Council of Europe (2002). Recent demographic developments in Europe:

Demographic Yearbook 2002. Strasbourg: Council of Europe.

Demographic Research Institute of the Hungarian Central Statistical Office (2002). GGS (Gender and Generations Survey, first wave), "Turning Points of Life Course", Hungarian Social and Demographic Panel Survey. Budapest.

Kamaras, F. (2003). Family formation and childbearing. Demografia: Special Edition for the 40th Anniversary of the Demographic Research Institute, Klinger, A., (ed.), Vol. 46, 2003, Budapest.

Kaplan E.L. and Meier P. (1958). Non-parametric estimation from incomplete observations. Journal of the American Statistical Association 53: 457-481.

Lesthaeghe, R. and Surkyn, J. (2002). New forms of household formation in Central and Eastern Europe: are they related to newly emerging value orientations? UN ECE Economic Survey of Europe 2002, 1:197-216.

Lillard, L. A. and Panis C.W.A. (2003). aML Multilevel Multiprocess Statistical Software, Version 2.0, User's Guide, Econware, Los Angeles CA.

Manting, D. (1996). The changing meaning of cohabitation and marriage. European Sociologican Review 12(1): 53-65.

Philipov, D. and Kohler H.-P. (2001). Tempo effects in the fertility decline in Eastern Europe: Evidence from Bulgaria, the Czech Republic, Hungary, Poland and Russia. European Journal of Population 17(1): 37-60.

Oppenheimer, V.K. (1988). A theory of marriage timing. American Journal of Sociology 94(3): 563-591.

Pongracz, T. and Speder, Z. (2003). Marriage and cohabitation. Demografia: Special Edition for the 40th Anniversary of the Demographic Research Institute, Klinger, A., (ed.), Vol. 46, 2003, Budapest.

Speder, Z. (2003). Fertility behaviour in a period of economic pressures and growing opportunities - Hungary, the 1990s. Population of Central and Eastern Europe: Challenges and Opportunities, Kotowska, E. and Jozwiak, J. (eds.). 2003, Warsaw.

Speder, Z. (forthcoming). The rise of cohabitation as a first union and some neglected factors of recent demographic developments in Hungary. Demografia: English Edition, 2005, Budapest. 


\section{Appendix}

Table A1: The transition to a first cohabitation: Data cleaning procedures

\begin{tabular}{|c|c|}
\hline \multicolumn{2}{|c|}{ Cohabitation } \\
\hline Original sample size & 8931 \\
\hline Exclusions & \\
\hline Roma & 218 \\
\hline Conception before age 15 & 25 \\
\hline Marriage before age 15 & 15 \\
\hline Cohabitation before age 15 & 28 \\
\hline Missings & \\
\hline Year of first direct marriage missing & 1 \\
\hline Month of first direct marriage missing & 8 \\
\hline Month of first cohabitation missing & 1 \\
\hline Year of first cohabitation missing & 3 \\
\hline $\begin{array}{l}\text { Married but could not say whether } \\
\text { cohabited before marriage or not }\end{array}$ & 33 \\
\hline Respondent's child without birth date & 8 \\
\hline Final sample size & 8591 \\
\hline Dependent events & 1070 \\
\hline
\end{tabular}

Source: own calculations based on GGS data (2001) 
Table A2: The transition to the dissolution of cohabitation vs. a subsequent marriage: Data cleaning procedures

\begin{tabular}{|c|c|c|}
\hline & $\begin{array}{l}\text { Dissolution of } \\
\text { Cohabitation }\end{array}$ & $\begin{array}{l}\text { Subsequent } \\
\text { Marriage }\end{array}$ \\
\hline Original sample size & 8931 & 8931 \\
\hline $\begin{array}{l}\text { Did not form union by cohabitation } \\
\text { Starting sample size }\end{array}$ & $\begin{array}{l}7721 \\
1210\end{array}$ & $\begin{array}{l}7721 \\
1210\end{array}$ \\
\hline Exclusions & & \\
\hline Roma & 98 & 98 \\
\hline Conception before age 15 & 8 & 8 \\
\hline Marriage before age 15 & 1 & 1 \\
\hline Cohabitation before age 15 & 28 & 28 \\
\hline Missings & & \\
\hline Month of first cohabitation missing & 1 & 1 \\
\hline Year of first cohabitation missing & 3 & 3 \\
\hline Respondent's child without birth date & 1 & 1 \\
\hline Cohabitation starting after censoring & 4 & 4 \\
\hline Final sample size & 1066 & 1066 \\
\hline Dependent events & 291 & 500 \\
\hline
\end{tabular}

Source: own calculations based on GGS data (2001) 